\title{
Short-term dispersal of Fukushima-derived radionuclides off Japan: modeling efforts and model-data intercomparison
}

\author{
I. I. Rypina ${ }^{1}$, S. R. Jayne ${ }^{1}$, S. Yoshida ${ }^{1}$, A. M. Macdonald ${ }^{1}$, E. Douglass ${ }^{2}$, and K. Buesseler ${ }^{3}$ \\ ${ }^{1}$ Department of Physical Oceanography, Woods Hole Oceanographic Institution, Woods Hole, MA 02543, USA \\ ${ }^{2}$ Naval Research Laboratory, Stennis Space Center, MS 39529, USA \\ ${ }^{3}$ Department of Marine Chemistry and Geochemistry, Woods Hole Oceanographic Institution, Woods Hole, MA 02543, USA
}

Correspondence to: I. I. Rypina (irypina@whoi.edu)

Received: 14 November 2012 - Published in Biogeosciences Discuss.: 30 January 2013

Revised: 28 May 2013 - Accepted: 18 June 2013 - Published: 24 July 2013

\begin{abstract}
The Great East Japan Earthquake and tsunami that caused a loss of power at the Fukushima nuclear power plants (FNPP) resulted in emission of radioactive isotopes into the atmosphere and the ocean. In June of 2011, an international survey measuring a variety of radionuclide isotopes, including ${ }^{137} \mathrm{Cs}$, was conducted in surface and subsurface waters off Japan. This paper presents the results of numerical simulations specifically aimed at interpreting these observations and investigating the spread of Fukushima-derived radionuclides off the coast of Japan and into the greater Pacific Ocean. Together, the simulations and observations allow us to study the dominant mechanisms governing this process, and to estimate the total amount of radionuclides in discharged coolant waters and atmospheric airborne radionuclide fallout. The numerical simulations are based on two different ocean circulation models, one inferred from AVISO altimetry and NCEP/NCAR reanalysis wind stress, and the second generated numerically by the NCOM model. Our simulations determine that $>95 \%$ of ${ }^{137} \mathrm{Cs}$ remaining in the water within $\sim 600 \mathrm{~km}$ of Fukushima, Japan in mid-June 2011 was due to the direct oceanic discharge. The estimated strength of the oceanic source is $16.2 \pm 1.6 \mathrm{PBq}$, based on minimizing the model-data mismatch. We cannot make an accurate estimate for the atmospheric source strength since most of the fallout cesium had left the survey area by midJune. The model explained several key features of the observed ${ }^{137} \mathrm{Cs}$ distribution. First, the absence of ${ }^{137} \mathrm{Cs}$ at the southernmost stations is attributed to the Kuroshio Current acting as a transport barrier against the southward progression of ${ }^{137} \mathrm{Cs}$. Second, the largest ${ }^{137} \mathrm{Cs}$ concentrations were associated with a semi-permanent eddy that entrained ${ }^{137} \mathrm{Cs}$ -
\end{abstract}

rich waters, collecting and stirring them around the eddy perimeter. Finally, the intermediate ${ }^{137} \mathrm{Cs}$ concentrations at the westernmost stations are attributed to younger, and therefore less Cs-rich, coolant waters that continued to leak from the reactor in June of that year.

\section{Introduction}

\subsection{Background}

In March of 2011 the Great East Japan Earthquake, a massive offshore earthquake, and resulting tsunami and aftershocks that wreaked devastation upon northern Japan also caused a loss of power at the Fukushima Dai-ichi nuclear power plants (FNPP) situated on the coast at $37^{\circ} 25^{\prime} \mathrm{N}, 141^{\circ} 2^{\prime} \mathrm{E}$. The subsequent destabilization caused direct emission of radioactivity through explosive release of radioactive materials into the atmosphere and leakage of coolant water discharge into the ocean (Chino et al., 2011; Butler, 2011; NSCJ, 2011). The atmospheric contamination and fallout were measured both near the site (Uematsu et al., 2012; MEXT, 2011a; Toyoshima et al., 2011) and globally (e.g. Preparatory Commission for the Comprehensive Nuclear-Test-Ban Treaty Organization, see Fig. 1 of Kristiansen et al., 2012; Table 5 of Stohl et al., 2012; National Atmospheric Deposition Program; Fig. 1 of Wetherbee et al., 2011), and while the nearshore (within $30 \mathrm{~km}$ of the coast) ocean discharge was monitored by both the Japanese government (MEXT, 2011b) and the power company (TEPCO, 2011) for the first few 
months, the spread of radiation into the greater Pacific went largely unobserved (Buesseler et al., 2011).

\subsection{KOK cruise}

Not quite three months after the first leakage into the ocean (30 May-16 June 2012), a cruise of international collaborators from 13 different institutions aboard the R/V Ka'imikai-o-Kanaloa (KOK) occupied an offshore survey area (Fig. 1b). Extending out $600 \mathrm{~km}$ from the coast (34$37^{\circ} \mathrm{N}, 142-147^{\circ} \mathrm{E}$ ), this cruise took samples to measure a variety of radionuclide isotopes including ${ }^{137} \mathrm{Cs}$ and ${ }^{134} \mathrm{Cs}$ in surface and subsurface waters and in biota (Buesseler et al., 2012). The KOK cruise also included a physical oceanography component focused on the dynamics of the ocean waters advecting and mixing the radioactive discharge. As part of this component of the project, 24 drifters were deployed to capture circulation features contemporaneous with the cruise and to follow the evolution of surface water parcels into the future. Hydrographic profiles (temperature, salinity) accompanied by the oxygen, nutrient and chemical isotope sampling were performed, and underway, direct velocity measurements were procured using the shipboard Acoustic Doppler Current-meter Profiler (SADCP).

\subsection{Goal}

Here, we use numerical modeling to investigate the dominant mechanisms governing the short-term spread of radiation within the North Pacific to interpret the physical components of the $K O K$ observations, and to place the radioactive isotope concentration estimates (Buesseler et al., 2012) in the context of the ocean circulation. The observed data set from the $K O K$ cruise and the numerical models used are presented in the next section. Section 3 discusses the simulated spread of radioactive isotopes, specifically ${ }^{137} \mathrm{Cs}$, from both the direct ocean discharge and from the airborne fallout using observation-based 2-D velocity fields. Section 4 considers the effects of 3-D circulation on the spreading of ${ }^{137} \mathrm{Cs}$. The last section concludes with a discussion of the results.

\section{Data and models}

\section{$2.1 \quad K O K$ cruise data}

To investigate the Lagrangian particle dispersion from the Fukushima region, 24 satellite-tracked surface drifters equipped with GPS, temperature and drogue tension sensors were released in June 2012 as part of the KOK cruise. The drifters were deployed at 20 locations, with 2 sets of double releases and one triplet release at the near-shore stations. Figure 1a shows drifter tracks from the time of release through 3 August 2012. All buoys were initially attached to drogues and advected by near-surface currents at $15 \mathrm{~m}$ depth. In early August, after traveling southward with a weak coastal cur- rent, 8 drifters grounded on the Japanese coast. Another 2 drifters lost their drogues within a few months to a year of their initial release. This analysis uses the quality-controlled drifter data, optimally interpolated to $6 \mathrm{~h}$ intervals ${ }^{1}$.

CTD casts were performed and water samples for the radionuclide isotope analysis were collected at 50 stations spanning the area extending from 50 up to $600 \mathrm{~km}$ off Japan. Additional underway water sampling was performed between the stations. Collected samples revealed the presence of ${ }^{137} \mathrm{Cs}$ and ${ }^{134} \mathrm{Cs}$ (Buesseler et al., 2012). As indicated by the close-to-unity ratio of ${ }^{134} \mathrm{Cs}$ to ${ }^{137} \mathrm{Cs}$ isotopes, which have quite different half-lives (roughly 2 and $30 \mathrm{yr}$, respectively), it was concluded that all ${ }^{134} \mathrm{Cs}$ found in $K O K$ samples was Fukushima-related (Buesseler et al., 2012). This result is consistent with Honda et al. (2012) who also reported that the ratio of ${ }^{134} \mathrm{Cs}$ to ${ }^{137} \mathrm{Cs}$ isotopes was about 1 in many seawater samples taken one month after the accident. A map of ${ }^{134} \mathrm{Cs}$ concentrations in surface waters resulting from the $K O K$ cruise is shown in Fig. 1b, and the vertical profiles of ${ }^{134} \mathrm{Cs}$ are shown in Fig. 1c. Note that although we use ${ }^{134} \mathrm{Cs}$ to identify Fukushima waters, the short-term spreading of the two Cs isotopes in the ocean would be similar, so they can be used interchangeably in the model.

\subsection{Source functions}

There were two distinct sources of Fukushima-related contamination to the ocean: the localized direct discharge of radioactive coolant waters into the near-shore ocean (here referred to as the "oceanic source"), and more widespread fallout of airborne radionuclides that were released to the atmosphere during FNPP explosions and then precipitated into the ocean (referred to as the "atmospheric source"). The concentration of ${ }^{137} \mathrm{Cs}$ in the coolant waters was monitored and the resulting time series has been reported in Buesseler et al. (2011). We use this measured time series (Fig. 2 top) to represent the oceanic source in our modeling efforts. What is less well constrained is the total amount of the released ${ }^{137} \mathrm{Cs}$ or, equivalently, the magnitude of the direct discharge source. Available direct discharge source estimates vary from 3.5 PBq according to Tsumune et al. (2011) to $22 \mathrm{PBq}$ reported by Bailly du Bois et al. (2012). Our results suggest that the intermediate source strength of about $16.2 \mathrm{PBq}$ gives the best agreement between the $K O K$ observations and our modeling efforts, so we use this value for our simulations in Sect. 3.2. We will come back to the question of total source strength in Sect. 3.4.

The temporal and spatial distributions of the precipitated ${ }^{137}$ Cs over the Pacific Ocean were, for the most part, unmeasured. The source function for the airborne ${ }^{137} \mathrm{Cs}$ thus has to be deduced from numerical simulations, such as those of Chino et al. (2011), Morino et al. (2011), or Stohl et

\footnotetext{
${ }^{1}$ Available at: http://osprey.bco-dmo.org/dataset.cfm?id= $14069 \backslash \&$ flag=view
} 

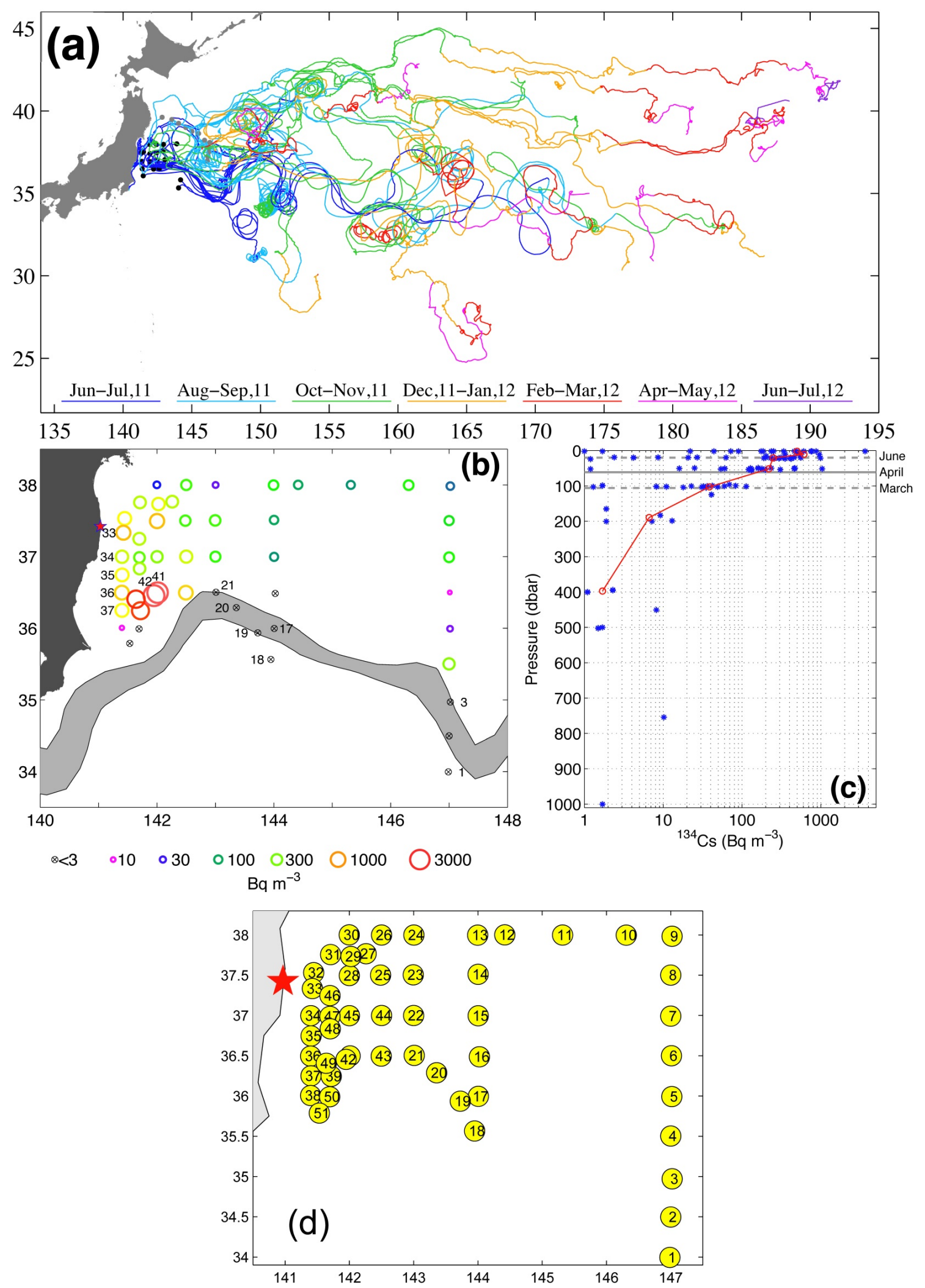

Fig. 1. (a) Color-coded tracks of $24 \mathrm{KOK}$ and 12 Mirai cruise drifters. Initial positions are marked by black and gray dots for the $K O K$ and Murai drifters, respectively. (b) Concentration of ${ }^{134} \mathrm{Cs}$ in surface water. Gray shading shows the average position of the Kuroshio Current. (c) $K O K$-observed water column distribution of ${ }^{134} \mathrm{Cs}$. Mean vertical profile of ${ }^{134} \mathrm{Cs}$ is shown in red. $K O K$ area averaged mixed-layer depths in March, April and June estimated from Argo are shown by gray lines. (d) $K O K$ station numbers and positions. 
al. (2012). We rely in our analysis on daily ${ }^{137} \mathrm{Cs}$ deposition patterns from Stohl et al. (2012) (see Fig. 2 bottom for the spatial pattern of the cumulative ${ }^{137} \mathrm{Cs}$ that had precipitated over the North Pacific by 20 April 2011). However, we use the total atmospheric source strength that gives the best agreement with the $K O K$ measurements. The highest limit of our estimated atmospheric source strength is $11 \mathrm{PBq}$, which corresponds to about $40 \%$ of that estimated by Stohl et al. (2012). We use this source strength of $11 \mathrm{PBq}$ for our simulations in Sect. 3.3. More details on the source strength estimation will be given in Sect. 3.4.

\subsection{Modeling the spreading of ${ }^{137} \mathrm{Cs}$}

Over the last two years there have been a number of numerical modeling studies aimed at assessing the aftermath of the Fukushima disaster (e.g., Tsumane et al., 2011, 2013; Kawamura et al., 2011; Estournel et al., 2012; Miyazawa et al, 2012; Masumoto et al., 2012; Bailly du Bois et al., 2012). Forward numerical models have allowed simulation of the spread of radioactive waters into the ocean. Inverse modeling efforts have been useful in constraining the source amplitudes of both the oceanic direct discharge and atmospheric fallout sources. The main goals of this investigation differ from this prior work in two respects. First, we focus on providing the physical oceanographic interpretation of the patterns observed by the KOK survey (Fig. 1b). Second, we investigate the general utility of data-based velocity fields for realistically reproducing the dispersal of passive tracers in the ocean over a time scale of several months.

We use two different estimates of the oceanic circulation to simulate the spreading of contaminated waters. The first one is observation-based and combines daily nearsurface geostrophic currents (on a Mercator $1 / 3^{\circ}$ grid) from AVISO with 6-hourly Ekman velocities (on a $2^{\circ} \times 2^{\circ}$ grid) based on the NOAA NCEP/NCAR wind stresses ${ }^{2}$. Wind stress at $10 \mathrm{~m}$ height, $\tau$, was converted to ocean velocity at $15 \mathrm{~m}$ depth, $u_{\mathrm{Ek}}$ and $v_{\mathrm{Ek}}$, using the Ralph and Niiler (1999) formula $u_{\mathrm{Ek}}+i v_{\mathrm{Ek}}=\beta e^{-i \theta} /(f \rho)\left(\tau_{x}+i \tau_{y}\right) / \sqrt{ }|\tau|$, where $\rho=1.027 \mathrm{~kg} \mathrm{~m}^{-3}$ is the assumed seawater density, $f$ is the Coriolis parameter, $\theta=55^{\circ}$ is the rotation angle of the Ekman current, and $\beta=0.065 \mathrm{~s}^{-1 / 2}$. The pros of this observation-based velocity are its reliability and its global coverage; the cons are the sparse temporal and spatial resolution, its two-dimensional nature, and the absence of ageostrophic components (other than Ekman). To account for lateral diffusion and the influence of the unresolved scales, a small stochastic velocity (taken, with random sign, from the normal distribution with a standard deviation of $5 \mathrm{~cm} \mathrm{~s}^{-1}$ ) was added to the sum of geostrophic and Ekman velocities. We have carefully checked that the results of our simulations

\footnotetext{
${ }^{2}$ http://www.esrl.noaa.gov/psd/data/gridded/data.ncep. reanalysis.derived.surfaceflux.html
}
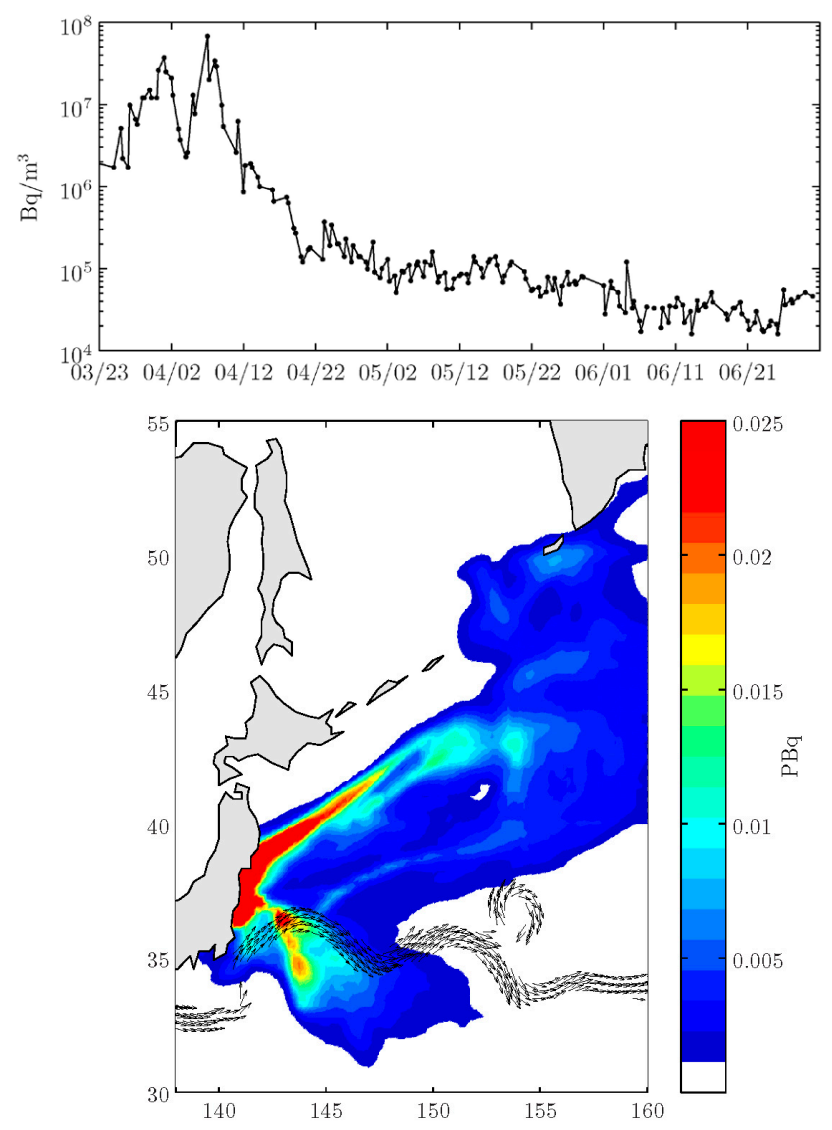

Fig. 2. (top) The time series of the concentration of ${ }^{137} \mathrm{Cs}$ in the coolant waters. Figure adapted from Buesseler et al. (2011). (bottom) Cumulative ${ }^{137} \mathrm{Cs}$ that had precipitated over the North Pacific by 20 April 2011. Figure adapted from Stohl et al. (2012). Black arrows indicate mean Kuroshio Current.

are not sensitive to the specifics of this stochastic velocity field, but we list these details for the sake of completeness.

The second velocity field that we used comes from the Navy Coastal Ocean Model (NCOM), a high-resolution numerical model (Barron et al., 2004, 2006). A regional model with $3 \mathrm{~km}$ horizontal resolution was nested with open boundaries within the HYCOM global $1 / 8^{\circ}$ model. The model had a hybrid vertical coordinate system, with $15 z$ levels at the top and 35 density-defined levels underneath, for a total of 50 vertical levels. The model was forced with wind and heat fluxes from the Coupled Ocean/Atmosphere Mesoscale Prediction System for the Western Pacific (COAMPS_WPAC). Tides at the boundaries were provided by the Oregon State Model (Egbert and Erofeeva, 2002). SSH, SST and available $T-S$ profile data from the Naval Oceanographic Office were assimilated into this model using optimal interpolation. The model was run each day, assimilating the data from the previous day and providing a $48 \mathrm{~h}$ forecast. One-day segments in the beginning of each run were then stacked together to create a longer time series covering the time interval from 
mid-March to the end of June 2011. There were discontinuities in the velocity field between the end of one day and the beginning of the next day, but these were small and for our purposes did not create any known issues. Unlike our observation-based circulation, NCOM 3-D velocities varied with depth throughout the water column, and had the advantage of better spatial and temporal resolution than provided by observations. The disadvantages of NCOM were the smaller model domain and the limited ability to match specific measured oceanic features, such as the exact position of the Kuroshio Current and the mesoscale eddies present during the spring of 2011, with the model estimate of the circulation field.

Comparison between the observation- and NCOM-based velocity fields is presented in Fig. 3. Compared to the observation-based model, NCOM generally overestimates the mean Kuroshio velocity (by up to $0.6 \mathrm{~m} \mathrm{~s}^{-1}$ in some areas), but slightly underestimates the mean currents throughout the rest of the domain. The general shape of the mean Kuroshio Current is captured relatively well in NCOM, but the exact position of meanders and mesoscale eddies is misplaced slightly in NCOM compared to observations. The variability in the eddy velocities is of the same order in the two models, with the highest variability in the general area of the Kuroshio Extension.

Spreading of ${ }^{137} \mathrm{Cs}$ is modeled using a Lagrangian framework by repeatedly releasing large numbers of simulated water parcels inside the source domain, over the full duration of the source time series. These water parcels are advected by the velocity fields described above and their trajectories are estimated using a fixed-step (RK4 for runs with the stochastic velocity component) or variable-step (RK4(5) for runs without the stochastic velocity component) Runge-Kutta integration scheme with bilinear interpolation in time and space between grid points. The exponential decay of ${ }^{137} \mathrm{Cs}$ concentration from the initial source value, with half-life of 30.16 years, is applied to estimate the concentration of ${ }^{137} \mathrm{Cs}$ following each water parcel ${ }^{3}$. Our model does not take into account the small fraction of ${ }^{137} \mathrm{Cs}$ in the particulate phase. The Lagrangian model provides an intuitive framework that illuminates the physical mechanisms by which the contaminated waters were brought from the source region to their position at any given time. The disadvantage of this framework is its numerical intensity due to the large number of the released water parcels and the simplified way in which the calculation treats the diffusion process (diffusivity is assumed to be spatially uniform and isotropic). As the number and frequency of the released parcels increases, the resulting Lagrangian distribution of ${ }^{137} \mathrm{Cs}$ approaches that estimated from an Eulerian calculation with the corresponding value of diffusivity.

\footnotetext{
${ }^{3}$ Slightly different half-life values of 30.05 and $30.02 \mathrm{yr}$ can be found in the Monographie BIPM-Comments, Vol1-4 (2008) and Browne et al. (1986), respectively, but these small differences are not relevant to the timescales investigated here.
}

To validate the process, the results of our simulations were tested to ensure that they were not overly sensitive to the further increases in the number of the released parcels. Using twice the number of fluid parcels leads to only a small change in the simulated June concentrations of Cs (see Appendix B). The lack of sensitivity to such an increase suggests that the observed distribution of ${ }^{137} \mathrm{Cs}$ is fairly close to the limiting value (i.e., for infinitely many parcels).

\section{Short-term dispersal of ${ }^{137} \mathrm{Cs}$}

\subsection{Real and simulated drifters}

To validate, and gain some confidence in, the velocity fields, we start this section by comparing the measured drifter trajectories (Fig. 4a) to those computed using the observationbased and numerically simulated velocities (Fig. 4c and e). Since the focus here is on the short-term dispersal of ${ }^{137} \mathrm{Cs}$ and on comparison with the KOK cruise observations, drifters are only compared to our models until 30 June. By that time, out of 24 drifters released, 11 were entrained in the Kuroshio and moving eastward with the current, 1 was captured by the cyclonic mesoscale eddy south of the Kuroshio, and 12 were still recirculating near-shore and remained west of $144^{\circ} \mathrm{E}$. These statistics are fairly well captured by the observation-based simulated drifters (Fig. 4c), in which 14 drifters were entrained into the Kuroshio, 7 recirculated near-shore, 2 ended up south of Kuroshio (one of which was trapped by the model eddy representing the observed eddy seen in the upper panel, 4a), and 1 drifter headed north. The smaller number of simulated drifters staying in the near-shore area is not surprising given that the near-shore circulation features are not well resolved by altimetry. The overall shape and extent of the distribution of the simulated drifters (Fig. 4c) is similar to that observed (Fig. 4a) with the Kuroshio meanders and the cyclonic mesoscale eddy at the correct locations. Note, however, that the simulated drifters do not travel as far east as the real drifters. Comparison of real and NCOM-simulated drifters (Fig. 4e) shows marginal agreement: 6 drifters entrained into the Kuroshio, 1 drifter went south of Kuroshio (this one, however, shows clockwise rotation), and 17 drifters stayed near-shore. The axis of the Kuroshio Current and the positions of the meanders and the eddy are displaced slightly compared to Fig. 4a and c. The Kuroshio in the NCOM model seems to be less efficient in entraining and transporting fluid, while the nearshore recirculation features are extremely effective in keeping fluid from moving eastward. To make the comparison between the real and simulated drifters more quantitative, the domain is divided into $1^{\circ} \times 1^{\circ}$ bins and the number of drifters visiting each bin is counted. The resulting maps of bin counts are shown in panels $4 \mathrm{~b}, 4 \mathrm{~d}$ and $4 \mathrm{f}$, respectively, for real, observation-based and NCOM-based simulated drifters. The correlation coefficient between the real 

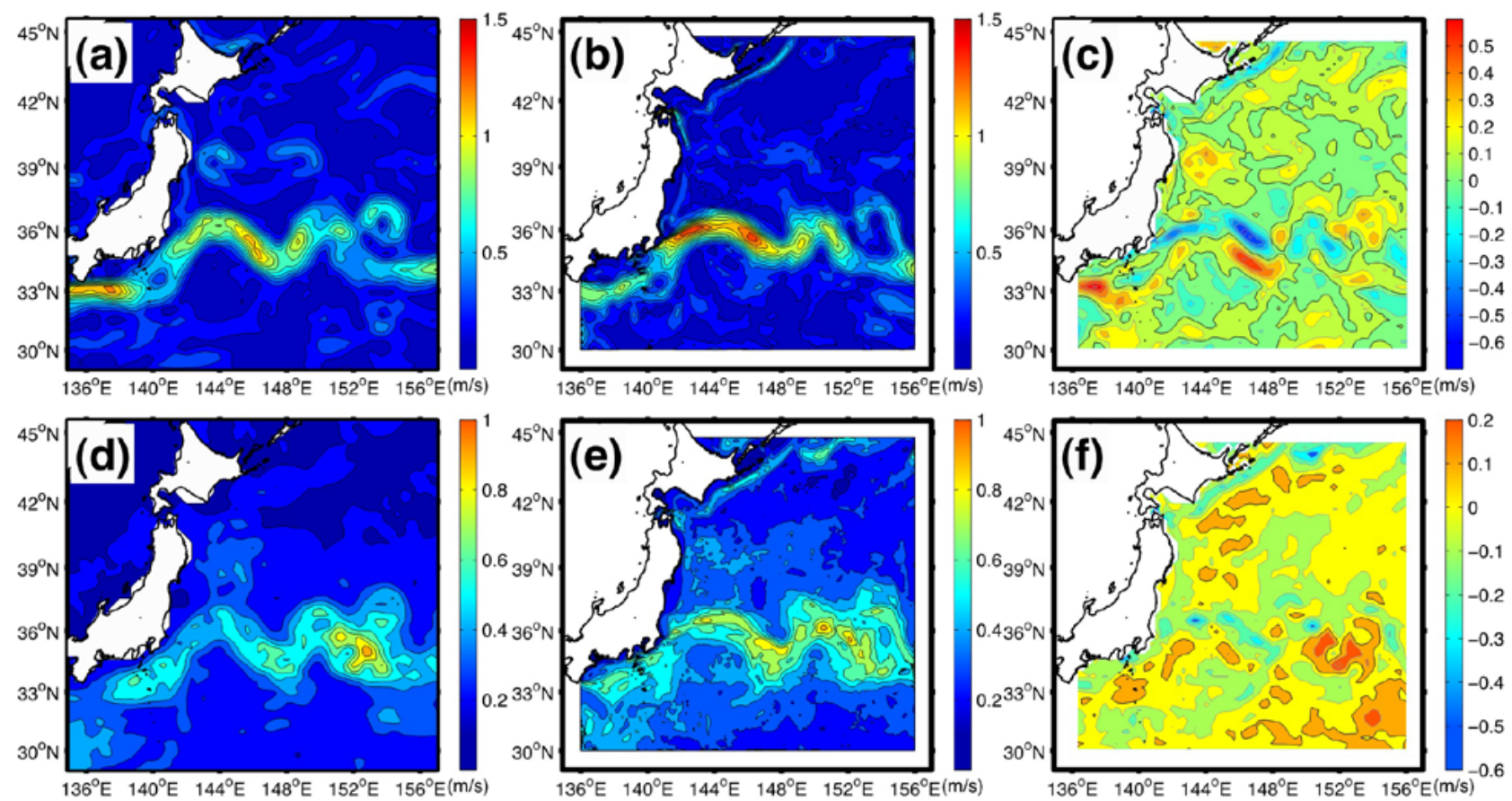

Fig. 3. (a) Time-mean currents for the observation-based model; (b) time-mean NCOM velocities averaged over the top 25 meters; (d) standard deviation of eddy velocities for the observation-based model; (e) standard deviation of eddy velocities for the NCOM model; (c, f) differences in means and standard deviations between the two models. $(\mathbf{c})=(\mathbf{a})$ minus $(\mathbf{b})$, and $(\mathbf{f})=(\mathbf{d})$ minus $(\mathbf{e})$. The period of data for this calculation is 14 March 2011 to 31 July 2011.

and observation-based maps is 0.95 , and between the real and NCOM-based map is 0.89 , suggesting that both approaches are reasonable, but that the observation-based approach provides a slightly more realistic outcome.

\subsection{Spreading of ${ }^{137} \mathrm{Cs}$ from the ocean source}

The spreading of a passive tracer in the ocean is governed by two processes, advection (stirring) and diffusion (mixing) (Eckart, 1948). Advection tends to distort the initial distribution of a tracer by stretching and folding, which produces elongated filaments or streaks that are then stretched and folded again. As the streaks become longer, narrower and more convoluted, gradients of concentration get larger and diffusion comes into play. Concentrated streaks start to fade, diffuse away and finally disappear, leaving behind a wellmixed homogenized fluid. In an ideal situation, when the advective velocity is known at all scales, mixing is simply due to the molecular diffusion. In reality, however, velocity is rarely known at small scales so the un- or under-resolved submesoscale features have to be accounted for by increased diffusion rather than by advection.

The ${ }^{137} \mathrm{Cs}$ concentrations resulting from the 2-D observation-based model have dimensions of $\mathrm{Bq} \mathrm{m}^{-2}$ and should be interpreted as depth-averaged values, $c_{\text {tot }}$. Comparison between the mean vertical profile of ${ }^{137} \mathrm{Cs}$ and the ARGO-based estimates of mixed-layer depth, $z_{\mathrm{ML}}$ indicates that the bulk (>90\%) of the observed ${ }^{137} \mathrm{Cs}$ lies above the April mixed layer (see Fig. 1c). Thus, the KOK observations suggest that, to a first approximation, the surface concentrations, $c_{\text {surf }}$ (in $\mathrm{Bq} \mathrm{m}^{-3}$ ), can be obtained from the depthaveraged values by dividing the latter by the mixed-layer depth, i.e., $c_{\text {surf }}=c_{\text {tot }} / z_{\mathrm{ML}}$. In our simulation we rely on $z_{\mathrm{ML}}$ estimates from ARGO profiles (Holte and Talley, 2009; Holte et al., 2010), but climatological mixed layers estimated from historical hydrographic data yield similar results. Due to the rapid warming and restratification of surface waters in late spring, the mixed-layer depth over the western Pacific Ocean in April/June is roughly one-half/one-fifth the March value. The ARGO-based March, April and June mean $z_{\mathrm{ML}}$ estimates averaged over the $K O K$ area are indicated by gray lines in Fig. 1c. The value of $c_{\text {surf }}$ is inversely proportional to $z_{\mathrm{ML}}$ and thus when $z_{\mathrm{ML}}$ is half as deep, $c_{\text {surf }}$ is doubled. In situations with temporally changing mixed-layer depths, such as the western Pacific waters in late spring, it is the deepest mixed layers that should be used for the conversion, because once ${ }^{137} \mathrm{Cs}$ has mixed down, it cannot un-mix and reconcentrate in the surface ocean, even when the mixed layer shoals later in spring. Additionally, this particular area is subject to little upwelling so fluid parcels generally do not rise up through the water column from depth. Rather, subsurface Cs left below the bottom of the receding mixed layer will be advected by subsurface currents at depth and will flow, to 

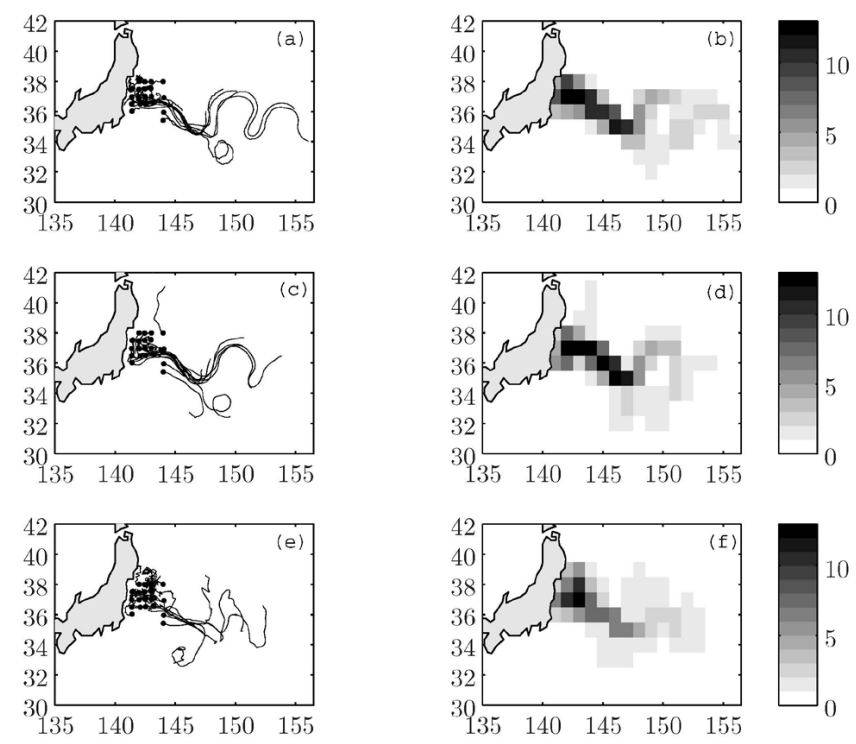

Fig. 4. Comparison between the real and simulated drifter tracks from deployment through 30 June 2011. (a), (c) and (e) on the left show the observed, the observation-based, and the NCOM-based trajectories, respectively. (b), (d) and (f) on the right show the number of drifters visiting each $1 \times 1^{\circ}$ bin for the observed, the observation-based and the NCOM-based drifters, respectively.

a first approximation, along subsurface isopycnal surfaces. Since the peaks of the atmospheric and oceanic sources occurred on 18 March and 7 April, respectively, we use the March/April $z_{\mathrm{ML}}$ values in modeling the spreading of ${ }^{137} \mathrm{Cs}$ from the atmospheric/oceanic sources.

The oceanic and atmospheric sources are markedly different from each other and so are the resulting ${ }^{137} \mathrm{Cs}$ distributions (Figs. 5 and 6). As discussed in Sect. 2.2. we use an oceanic/atmospheric source strength of $16.2 / 11 \mathrm{PBq}$. Notice, however, that the spreading pattern does not depend on the choice of the source strength. The oceanic source discharged large concentrations of ${ }^{137} \mathrm{Cs}$ into the Pacific Ocean directly off the coast of Japan. In our numerical simulations, the source domain was taken to be a $20 \times 20 \mathrm{~km}^{2}$ square centered at the FNPP location. The discharge peaked around 7 April 2011, but the coolant waters continued to leak from the reactor for several months, although with smaller ${ }^{137} \mathrm{Cs}$ concentrations (Buesseler et al., 2011). The oceanic source is thus prolonged in time but compact in space.

The discharged waters, stirred by the oceanic currents, form a wiggly streak of high ${ }^{137} \mathrm{Cs}$ concentration, extending approximately eastward off the coast of Japan and into the Pacific (Fig. 5 top left). This is in general agreement with the modeling results of Miyazawa et al. (2012) who reported that the modeled distribution of ${ }^{137} \mathrm{Cs}$ from the beginning of April and onward is strongly affected by the eastward-flowing Kuroshio Current. With time, the streak becomes increasingly convoluted due to the action of advection, and fuzzier as diffusion starts to mix together the high- concentration streak water with its lower-concentration surroundings (Fig. 5 top left through bottom right). By mid-June (the time of the $K O K$ cruise), the contaminated waters reach $170^{\circ} \mathrm{E}$ and $42^{\circ} \mathrm{N}$, staying mostly to the north of the Kuroshio (Fig. 5 bottom right). The homogenization process is well underway by this time, especially at the eastern end of the distribution, although the streaks have not been completely wiped away and are still quite strong in certain areas. Notice that even in June, the streak is still attached to the coast by one end because the coolant waters continued to leak out of the reactor. The amount of ${ }^{137} \mathrm{Cs}$ left in the $K O K$ area at the time of the cruise is about $17.5 \%$ of the total oceanic discharge, with $14 \%$ in the offshore $K O K$ area spanned by stations 1 to 17. The southern edge of the distribution is roughly aligned with the Kuroshio Current, suggesting that this strong current acts as a transport barrier, particularly over the western part of the Pacific Ocean where it is most strongly defined. Interestingly, Rypina et al. (2010) found that in the North Atlantic, the Gulf Stream also acts as a transport barrier. The similarity in these results suggests that plausibly it is typical for all strong oceanic currents to prevent cross-stream transport.

The distribution of ${ }^{137} \mathrm{Cs}$ also shows elevated values near the perimeters of several eddies, whereas concentrations near the eddy cores are generally small. Rypina et al. (2010) similarly observed an increase in phytoplankton concentration at the perimeter of coupled eddies (dipoles) in the Philippine Archipelago. Fluid exchange processes are different at the perimeter of an eddy compared to its core. At eddy perimeters the so-called "chaotic advection" mechanism is at play (Mancho et al., 2006; Rypina et al., 2010), which leads to the sequential stretching and folding of fluid elements and facilitates the exchange with the outer waters. Within the Lagrangian core of an eddy, on the other hand, a more "regular" state of motion exists where the behavior of fluid parcels is similar to that found in steady flows. Similar to the steady case, fluid parcels near the core follow paths around the center of the eddy without much exchange with outside fluid. This is why eddies are generally able to transport the water in their cores over long distances without "spilling" it along the way (Chelton et al., 2007; Early et al., 2011; Beron-Vera et al. 2013). The ability of oceanic eddies to trap fluid in their Lagrangian cores has been a subject of an ongoing research.

The three properties discussed above - the streakiness of the distribution, the role of the Kuroshio Current in preventing the southward spreading of ${ }^{137} \mathrm{Cs}$, and the high ${ }^{137} \mathrm{Cs}$ concentrations at the perimeters of eddies - are responsible for several key features in the observed ${ }^{137} \mathrm{Cs}$ distribution. We will come back to these points in Sect. 3.4.

\subsection{Spreading of ${ }^{137} \mathrm{Cs}$ from the atmospheric source}

The atmospheric source has a much wider spatial pattern than the oceanic source (Fig. 2), but the peak of the atmospheric source occurred about 3 weeks prior to the oceanic source peak, and the temporal duration of the atmospheric fallout 

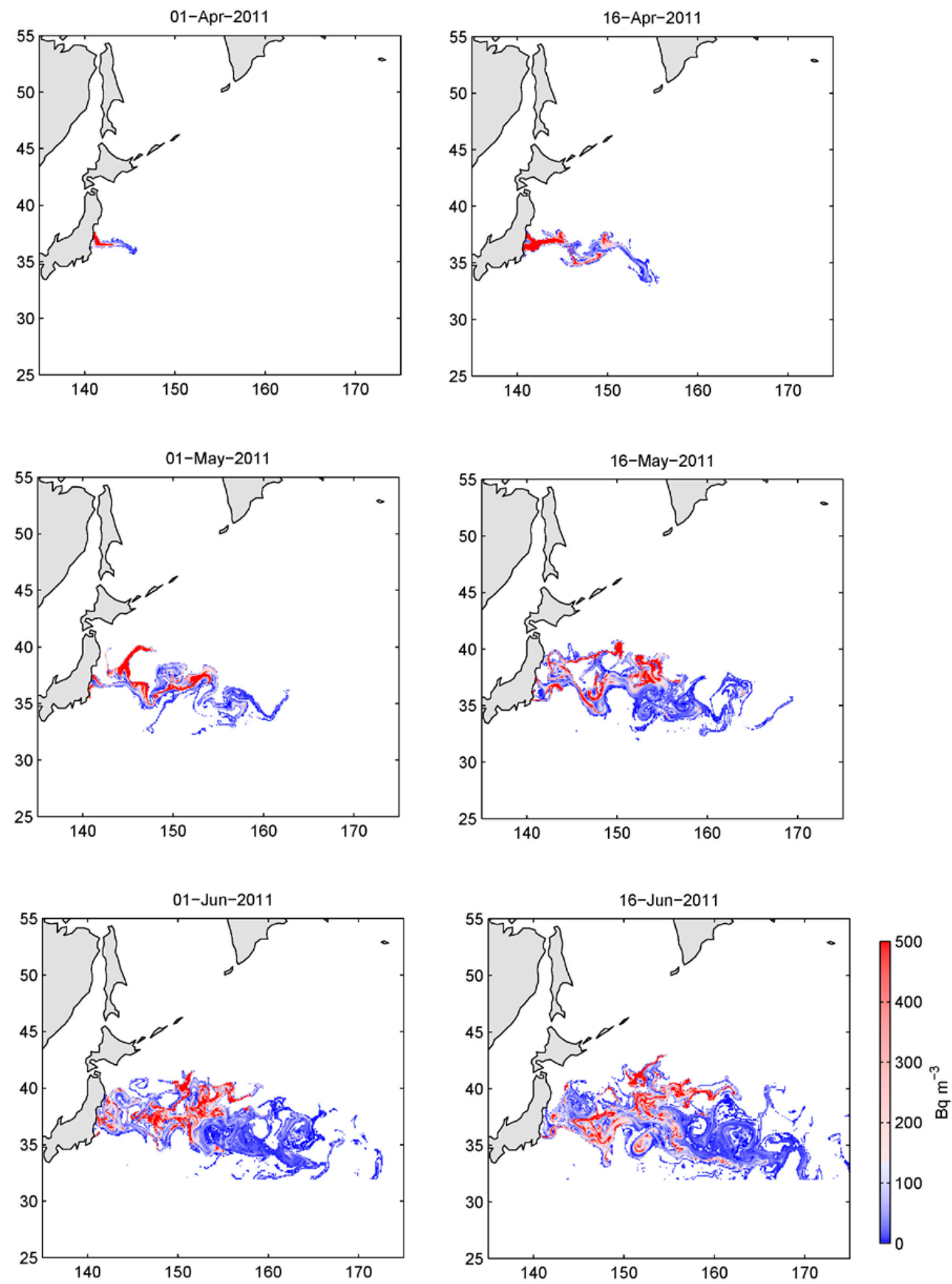

Fig. 5. Modeled ${ }^{137}$ Cs concentration within the mixed layer on select dates derived from the observation-based model for the oceanic source. Colors are saturated at $500 \mathrm{~Bq} \mathrm{~m}^{-3}$. The source domain is taken to be $20 \times 20 \mathrm{~km}^{2}$ square centered at the FNPP. Source strength is $16.2 \mathrm{PBq}$.

was shorter than the direct discharge (the time series for the atmospheric source ends on 20 April). Precipitation peaked on 18 March and decreased sharply afterwards. The defining spatial pattern for the atmospheric source shows two largescale (about $200 \mathrm{~km}$ wide and over $1000 \mathrm{~km}$ long) streaks extending roughly from the FNPP location to the northeast and southeast, with the southern streak reaching past the Kuroshio Current. The subsequent ocean spreading of ${ }^{137} \mathrm{Cs}$ from the atmospheric source (Fig. 6) covers much of the Pacific Ocean $\left(135-175^{\circ} \mathrm{E}\right.$ and from $\left.25-57^{\circ} \mathrm{N}\right)$ and, although the filaments are clearly visible in the resulting ${ }^{137} \mathrm{Cs}$ distributions, they are generally much wider than those from the compact oceanic source. Both the mean currents and the eddies are strongest in the general area of the Kuroshio Current and its extension, leading to the rapid advection of atmospheric fallout ${ }^{137} \mathrm{Cs}$ to the east and to vigorous stirring and 

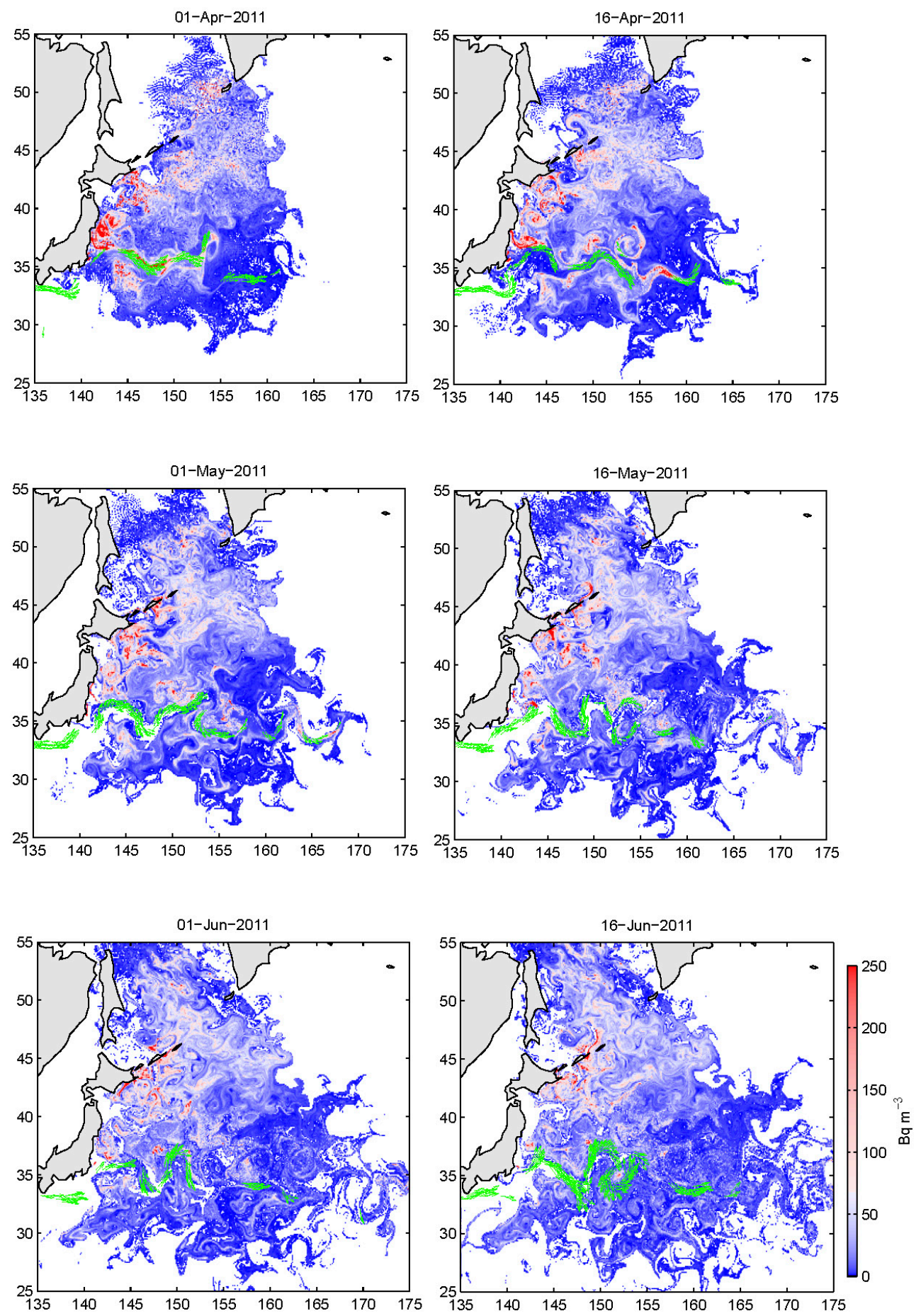

Fig. 6. Simulated ${ }^{137} \mathrm{Cs}$ concentration within the mixed layer on select dates from the atmospheric source using the observation-based model. The spatial and temporal patterns for the atmospheric source are from Stohl et al. (2012) with a source strength of 11 PBq. Green arrows indicate the modeled Kuroshio Current position.

filamentation at these latitudes. Unlike the oceanic source that lies entirely to the north of Kuroshio, the southern edge of the initial fallout distribution of ${ }^{137} \mathrm{Cs}$ lies to the south of the Kuroshio (Fig. 2b). Thus, the barrier effect of the current is not visible in the resulting ${ }^{137} \mathrm{Cs}$ distributions from the atmospheric source. The western part of the Kuroshio core is almost ${ }^{137} \mathrm{Cs}$-free starting from the beginning of May, because all the ${ }^{137} \mathrm{Cs}$-rich waters have been rapidly advected 
from this area to the east where they have been vigorously stirred and mixed with the surrounding water. The northern part of the ${ }^{137} \mathrm{Cs}$ distribution is less distorted from its initial shape than the southern part, with a large-scale blob of high ${ }^{137} \mathrm{Cs}$ concentration remaining at around $152^{\circ} \mathrm{E}$ and $45^{\circ} \mathrm{N}$ even as late as mid-June. The near-shore coastal area in front of the FNPP has low concentrations of ${ }^{137} \mathrm{Cs}$ and, unlike for the oceanic source, the streaks do not reach the coast in this region. The amount of ${ }^{137} \mathrm{Cs}$ left in the $K O K$ study area at the time of the cruise is about $4.5 \%$ of the atmospheric source, with most $(3.5 \%)$ in the offshore $K O K$ area spanned by stations $1-17$.

\subsection{Source amplitudes}

With the numerically estimated distributions of ${ }^{137} \mathrm{Cs}$ from the two sources and the $K O K$ data in hand, the source amplitudes for the atmospheric and oceanic sources can be estimated. For various amplitudes of both the atmospheric and ocean sources, $A_{\text {ocean }}$ and $A_{\text {atm }}$, we construct the simulated ${ }^{137}$ Cs map by "sampling" the numerical distributions of ${ }^{137} \mathrm{Cs}$ from the two sources at the times and positions of the $K O K$ stations. The source amplitudes, $A_{\text {ocean }}$ and $A_{\text {atm }}$, are then determined by minimizing the error function

$\mathrm{Er}=\frac{1}{N} \sum_{i=1}^{N}\left|A_{\text {ocean }} c_{\text {ocean }}^{i}+A_{\mathrm{atm}} c_{\mathrm{atm}}^{i}-c_{K O K}^{i}\right|$,

which represents the standard $L_{1}$-norm and quantifies the difference between the measured $\left(c_{K O K}^{i}\right)$ and simulated $\left(c_{\text {ocean }}^{i}\right.$ and $c_{\mathrm{atm}}^{i}$ ) concentrations of ${ }^{137} \mathrm{Cs}$, averaged over the stations. Over the range of source amplitudes $0<A_{\text {ocean }}<35 \mathrm{PBq}$ and $0<A_{\text {atm }}<25 \mathrm{PBq}$, the error function $\mathrm{Er}$ has a minimum at $A_{\text {ocean }}=16.2 \pm 1.6 \mathrm{PBq}$ (estimates range from 9.1 $\mathrm{PBq}$ to $17.8 \mathrm{PBq}$ with more values near the upper limit) and $A_{\mathrm{atm}}=0.5 \pm 2.7 \mathrm{PBq}$ (estimates range from $0 \mathrm{PBq}$ up to $11 \mathrm{PBq}$ with most values near the lower limit). The error bars correspond to one standard deviation (and value ranges indicate the smallest and largest estimates, respectively) computed using the bootstrapping procedure (Tukey, 1958) of sequentially eliminating one station and reevaluating the expression for the remaining stations. Note that theoretically a situation is possible where the error function could have two (or more) minima, e.g. one with a higher atmospheric and lower oceanic source estimate, and another with a lower atmospheric and higher oceanic source estimate. In practice, however, in every case the error function has a single minimum over the considered range of source amplitudes (see Appendix A).

Our estimates of the oceanic source strength, ranging from 9.1 $\mathrm{PBq}$ to $17.8 \mathrm{PBq}$ are significantly higher than the estimate of 3.5-3.6 PBq obtained by Tsumune et al. (2011, 2013), and are roughly consistent with estimates of Bailly du Bois et al. (2012), who reported a range of $10-34 \mathrm{PBq}$ for the direct discharge estimates. Our atmospheric source strength estimates, 0-11 PBq, correspond to less than half of the Stohl et al. (2012) estimates, who reported a range of $23-50 \mathrm{PBq}$ for the atmospheric fallout.

Our numerical simulations predict that most ( $>95 \%$ ) of ${ }^{137} \mathrm{Cs}$ left in the $K O K$ area in mid-June came from the direct oceanic discharge. This number was obtained by combining the lower/upper limit of our oceanic/atmospheric estimate with the percentage of ${ }^{137} \mathrm{Cs}$ remaining in the $\mathrm{KOK}$ area ( $17.5 \%$ and $4.5 \%$ for the oceanic and atmospheric releases, respectively; see Sects. 3.2-3.3):

$$
\begin{aligned}
& 17.5 \% \cdot(16.2-1.6) \mathrm{PBq} /(17.5 \% \cdot(16.2-1.6) \mathrm{PBq} \\
& +4.5 \% \cdot(0.5+2.7) \mathrm{PBq})=95 \% .
\end{aligned}
$$

This result agrees with Charette et al. (2013) who concluded, based on the radium isotope ratios, that the water sampled during the $K O K$ cruise shows a strong coastal signature. This conclusion is further supported by the ${ }^{90} \mathrm{Sr}$ measurements at the $K O K$ stations (Casacuberta et al., 2013). The distribution of ${ }^{90} \mathrm{Sr}$, which is much less volatile than ${ }^{137} \mathrm{Cs}$ and thus came almost entirely from the oceanic source, is similar to that for ${ }^{137} \mathrm{Cs}$, suggesting that both chemicals came from the same source.

It is important to note that our estimate for the atmospheric source amplitude is much less reliable than that for the oceanic source because most of the fallout atmospheric ${ }^{137} \mathrm{Cs}$ had moved out of the survey area by mid-June. Thus, the oceanic isotope concentrations observed during the $\mathrm{KOK}$ cruise, which are due almost entirely to the oceanic discharge of FNPP coolant waters, are ill-suited for constraining the total magnitude of the atmospheric input.

\subsection{Physical oceanographic view on the key features of the measured ${ }^{137} \mathrm{Cs}$ map}

Using modeled concentrations of ${ }^{137} \mathrm{Cs}$ in the mixed layer at times corresponding to select stations (Fig. 7), we can interpret some of the key features of the measured ${ }^{137} \mathrm{Cs}$ map. Since $\geq 95 \%$ of ${ }^{137} \mathrm{Cs}$ remaining in the $K O K$ area in June is derived from the direct oceanic discharge, we focus on the oceanic source in this subsection. First, the strong and direct influence of the Kuroshio Current, which acts as a transport barrier for the southward progression of ${ }^{137} \mathrm{Cs}$ from the oceanic source, manifests itself in the low concentrations at stations 1-3 (top row in Fig. 7) and 17-21 (2nd row in Fig. 7). All of these stations lie to the south of the instantaneous Kuroshio core, and thus the contaminated water from the oceanic source cannot reach them. This pattern agrees with the modeling results of Tsumane et al. (2013) (their Figs. 15 and 16), who also found the smallest Cs concentrations at southernmost $\mathrm{KOK}$ stations.

Second, the largest ${ }^{137} \mathrm{Cs}$ concentrations are found not at the stations closest to the FNPP but at stations 37, 46 and 41, 42 (bottom row in Fig. 7). The elevated ${ }^{137} \mathrm{Cs}$ values at these stations are associated with the action of the near-shore semi-permanent eddy that was present in the area from April to July. This strong and robust cyclonic eddy was entraining 

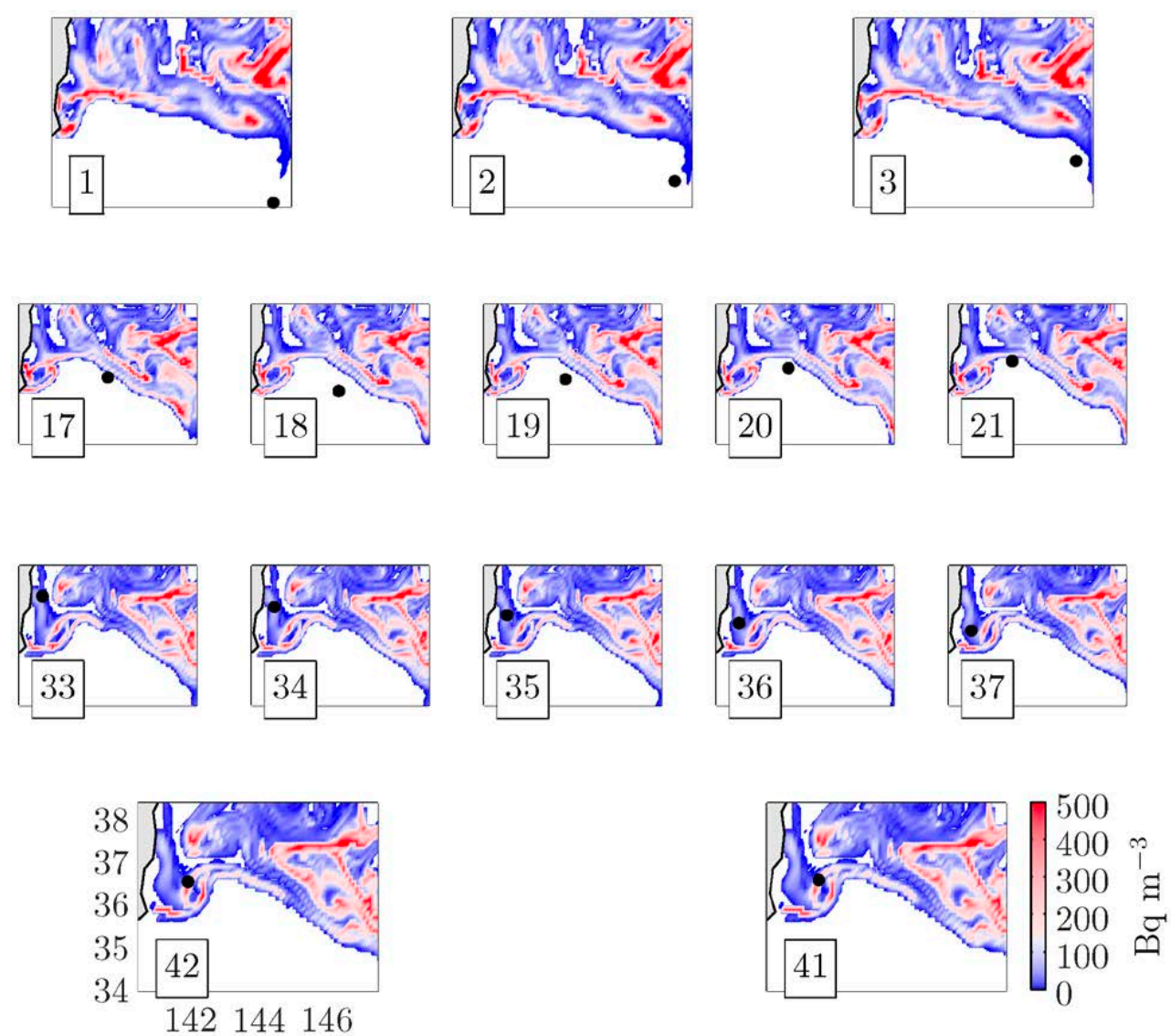

Fig. 7. Modeled mixed-layer ${ }^{137} \mathrm{Cs}$ concentration from the oceanic source (in color) at times corresponding to select stations. Black dot shows the station position. The number outlined in the lower left corner indicates station number (see Fig. 1d).

the contaminated water that leaked from the reactor into the cyclonic motion around the eddy perimeter. This circulation pattern not only built up the concentrations near the perimeter, but also delayed the eastward advection of ${ }^{137} \mathrm{Cs}$. The ${ }^{137}$ Cs-rich waters did not penetrate into the center of the eddy, so its core remained relatively ${ }^{137} \mathrm{Cs}$-free.

The third interesting observation concerns the westernmost stations 33 through 37, which sampled the streak of coolant water supplied by the continued leakage from the reactor in June (3rd row in Fig. 7). Again, this observation is in general agreement with Fig. 15 from Tsumane et al. (2013), which also shows the meridional elongated streak of contaminated water extending parallel to the coast about $40 \mathrm{~km}$ offshore (although the exact location of the streak seems to be shifted slightly to the east in their simulations compared to our modeling results and to the $K O K$ observations). The levels of ${ }^{137} \mathrm{Cs}$ at these stations are consistently elevated, but are not the highest values measured because the concentration of ${ }^{137} \mathrm{Cs}$ in the coolant water in June was already much reduced compared to its peak value in April. In agreement with the $K O K$ measurements, our modeling results suggest that the distribution of ${ }^{137} \mathrm{Cs}$ in mid-June was still filamentary and that the diffusion processes had not yet wiped away the high gradients in the ${ }^{137} \mathrm{Cs}$ field.

The station-by-station comparison between the measured and simulated ${ }^{137} \mathrm{Cs}$ concentrations at the $K O K$ stations is shown in Fig. 8. Here, the detection limit for ${ }^{137} \mathrm{Cs}$ is $1.5 \mathrm{~Bq} \mathrm{~m}^{-3}$ (Buesseler et al., 2012) so we have cut off our simulated ${ }^{137} \mathrm{Cs}$ concentrations at the same level for a fair comparison. Note also that unlike our simulated concentrations, which correspond to Fukushima-derived ${ }^{137} \mathrm{Cs}$, the measured values include both Fukushima-derived and pre-existing ${ }^{137} \mathrm{Cs}$ (the latter is at levels of $1-2 \mathrm{~Bq} \mathrm{~m}^{-3}$; Buesseler et al., 2011, 2012). The two curves in Figure 8 are in qualitative agreement with each other, showing min$\mathrm{ima/maxima} \mathrm{at} \mathrm{same} \mathrm{stations} \mathrm{(i.e.,} \mathrm{at} \mathrm{same} \mathrm{geographical} \mathrm{loca-}$ tions). The quantitative agreement is better for stations 1-27 than for the near-shore stations 28-51. This is plausibly because the distribution is extremely filamentary close to shore, more so than for the off-shore stations. ${ }^{137} \mathrm{Cs}$ concentrations in the near-shore area span several orders of magnitude, with very sharp changes in concentration from one station location to the next (Fig. 1b). Our observation-based model is not able to quantitatively match all of this variability due to its coarse spatial and temporal resolution, and the oversimplified 


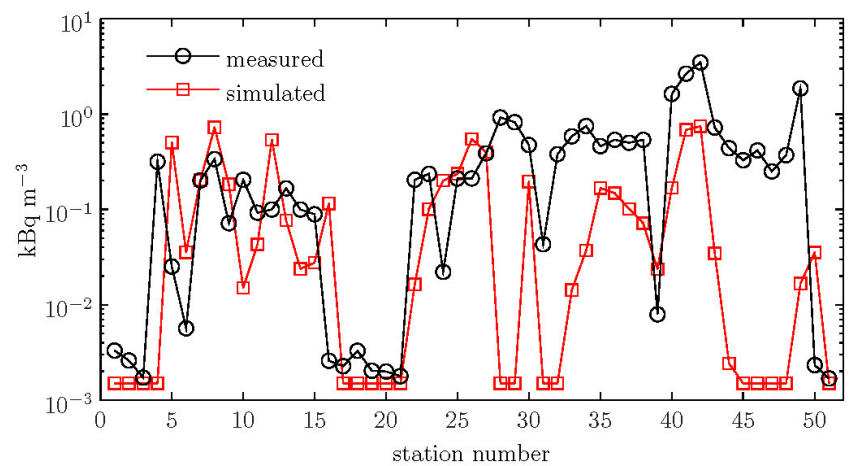

Fig. 8. Measured and simulated (using the observation-based model) estimates of ${ }^{137} \mathrm{Cs}$ surface concentration at the times and geographical locations corresponding to the $K O K$ stations. Here, the detection limit for ${ }^{137} \mathrm{Cs}$ is $1.5 \mathrm{~Bq} \mathrm{~m}^{-3}$ (Buesseler et al., 2012), therefore to simplify the comparison, the simulated ${ }^{137} \mathrm{Cs}$ concentrations have been cut off at the same level.

representation of diffusion processes. Despite some quantitative mismatch, the model is still useful in explaining the qualitative features of the observed Cs distribution. To conclude, despite several limitations, the numerical modeling provided a means for interpreting the $K O K$ observations in the context of the physical ocean circulation.

\section{Effects of the third dimension on the short-term dispersal of ${ }^{137} \mathrm{Cs}$}

The modeling results in the previous section relied on the two-dimensional near-surface observation-based velocity fields and ignored the effects of vertical velocity, vertical mixing and vertical shear. In this section we use the NCOM numerical model to investigate the effects of these processes. We again restrict our attention to the spreading of ${ }^{137} \mathrm{Cs}$ from the oceanic source only. As in the previous section, we use the measured time series of ${ }^{137} \mathrm{Cs}$ concentration in the coolant waters with a source strength of $16.2 \mathrm{PBq}$ and assume that the source occupies (horizontally) a $20 \times 20 \mathrm{~km}^{2}$ square centered at the FNPP location. In our 3-D analysis, however, the source concentrations are assigned not only to the water parcels at the surface, as in the previous section, but also at 10 evenly distributed subsurface layers spanning the upper $10 \mathrm{~m}$ of the water column. We then advect water parcels using 3-D NCOM velocities, and as before, apply the exponential decay of ${ }^{137} \mathrm{Cs}$ with half-life of $30.16 \mathrm{yr}$ following each water parcel. To account for vertical mixing within the near-surface mixed layer ${ }^{4}$, the depths and ${ }^{137} \mathrm{Cs}$ concentrations for water parcels within the mixed layer are adjusted every $6 \mathrm{~h}$. In particular, the domain is divided into $0.1^{\circ} \times 0.1^{\circ}$ degree lateral bins. In each bin the average mixed-layer con-

\footnotetext{
${ }^{4}$ The isopycnal formulation of NCOM does not explicitly resolve vertical velocities in the mixed layer.
}

centration is computed and then assigned to all parcels located within the mixed layer in that bin. The depths of the mixed layer parcels are also adjusted to be randomly distributed over the mixed layer in each bin. The number of parcels is kept the same throughout this procedure.

The resulting ${ }^{137} \mathrm{Cs}$ distributions at select dates are shown in Fig. 9. This figure suggests that from April until the end of June, most of the ${ }^{137} \mathrm{Cs}$ stayed within the surface mixed layer, occasionally penetrating down to greater depths at select times and locations (middle and right panels). There are two distinct processes by which ${ }^{137} \mathrm{Cs}$ can reach below the local mixed-layer depth. First, since the mixed-layer depth is spatially non-uniform, ${ }^{137} \mathrm{Cs}$ can be mixed down to the bottom of the mixed layer at a remote location, where the mixed layer is deep, and then be advected laterally by currents at depth to a location with a shallower mixed layer. Second, in regions of strong downwelling, ${ }^{137} \mathrm{Cs}$ can be brought below the mixed layer by the strong vertical velocities, and then again advected along the deep isopycnals by the lateral currents.

For comparison, Fig. 10 shows the mixed-layer distributions of ${ }^{137} \mathrm{Cs}$ from the 2-D NCOM simulation, where we advect parcels using the 2-D near-surface NCOM velocities averaged over the top $25 \mathrm{~m}$ of the water column, and then divide the 2-D concentrations by the mixed-layer depth at that location. The mixed-layer ${ }^{137} \mathrm{Cs}$ fields from the 2-D and 3$\mathrm{D}$ distributions are quite similar, suggesting that the effects of the vertical velocity and vertical shear on the short-term dispersal of ${ }^{137} \mathrm{Cs}$ are not particularly strong.

Overall, the NCOM-based ${ }^{137} \mathrm{Cs}$ distributions in Figs. 9 and 10 are qualitatively similar to those from the observationbased model (Fig. 5) in their shape, extent and major features. Both models predict that initially the discharged waters formed an elongated streak extending eastward from the FNPP. With time, high concentrations of ${ }^{137} \mathrm{Cs}$ progress further eastward into the Pacific, staying largely to the north of Kuroshio. Eventually the streaks become more convoluted and start to diffuse away. Compared to the observation-based model (Fig. 5), the streaks in the NCOM-based ${ }^{137} \mathrm{Cs}$ distributions (Figs. 9 and 10) are slightly wider and more diffusive (fuzzier). This is likely due to the action of rapidly varying small-scale features that are resolved by NCOM but not by the observation-based model. As we have already learned from the simulated drifters (Fig. 4), the exact position of the Kuroshio Current is displaced in NCOM simulations (Figs. 9 and 10) compared to the observation-based model (Fig. 5). Furthermore, although most of the ${ }^{137} \mathrm{Cs}$ remains to the north of the Kuroshio, the transport barrier associated with the Kuroshio is leakier in NCOM.

\section{Summary and discussion}

In this research, we used numerical modeling and observations from the $K O K$ cruise to investigate the short-term 

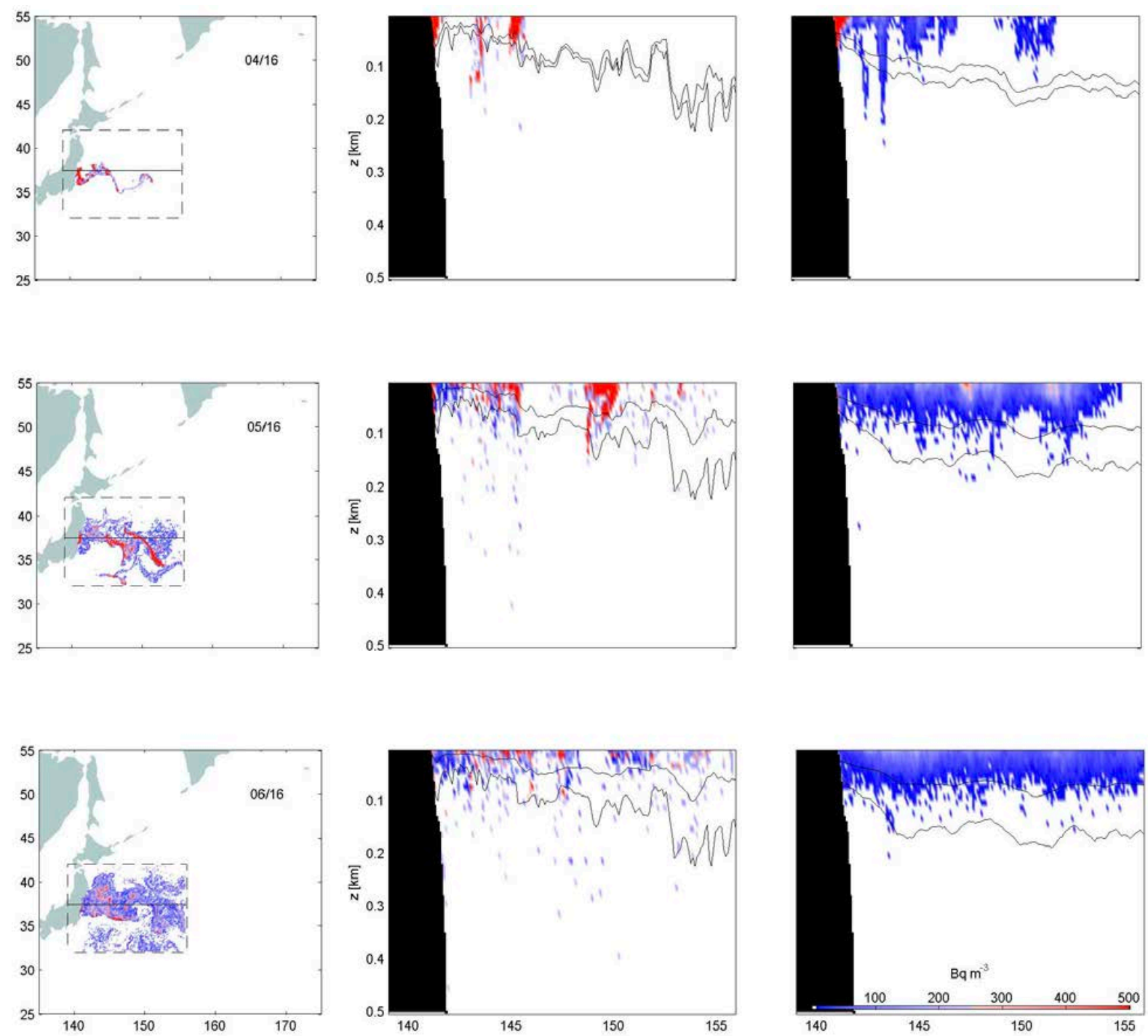

Fig. 9. NCOM-based model distributions of ${ }^{137} \mathrm{Cs}$ on select dates from the oceanic source. (left) Mixed-layer concentrations of ${ }^{137} \mathrm{Cs}$. Dashed lines show the model domain. Source characteristics as in Fig. 5. (middle) Vertical slice of the ${ }^{137}$ Cs field at the FNPP latitude (horizontal line in left panel). The mean and the deepest mixed-layer depth $(\mathrm{km})$ computed from 18 May until the corresponding date are shown as gray contours. (right) Latitude-averaged over the domain concentration of ${ }^{137} \mathrm{Cs}$. Latitude-averaged mean and deepest mixed-layer depth shown as gray contours.

spreading of Fukushima-derived radionuclides off the coast of Japan and into the Pacific Ocean. The numerical simulations were based on two different velocity fields, one inferred from AVISO altimetry and NCEP/NCAR reanalysis wind stresses, and another generated numerically by the NCOM model. Two sources of Fukushima-derived ${ }^{137} \mathrm{Cs}$ were used: the oceanic source due to the direct discharge of ${ }^{137} \mathrm{Cs}$-rich coolant waters near the FNPP, and the atmospheric source due to the widespread fallout of airborne ${ }^{137} \mathrm{Cs}$.

The results of our numerical simulations were compared to in-situ observations of ${ }^{137} \mathrm{Cs}$ concentrations from the $\mathrm{KOK}$ cruise that took place in June 2011 and provided water samples as far as $600 \mathrm{~km}$ east of the Japanese coast. Our simula- tions revealed that the bulk of the fallout atmospheric ${ }^{137} \mathrm{Cs}$ had moved out of the survey region by mid-June, so that most (>95\%) of the ${ }^{137} \mathrm{Cs}$ left in the KOK area at the time of the cruise came from the oceanic source. This conclusion is supported by the radium-based analysis of Charette et al. (2013), who reported a strong coastal signature in waters sampled during the KOK cruise. The result is further supported by the similarity between the measured ${ }^{90} \mathrm{Sr}$ and ${ }^{137} \mathrm{Cs}$ patterns, which suggests that both radionuclides came from the oceanic source (Casacuberta et al., 2013).

Comparison between the KOK measurements and the results of our numerical simulations allowed for the estimation of the source amplitudes yielding a range of $9.1-17.8 \mathrm{PBq}$ 

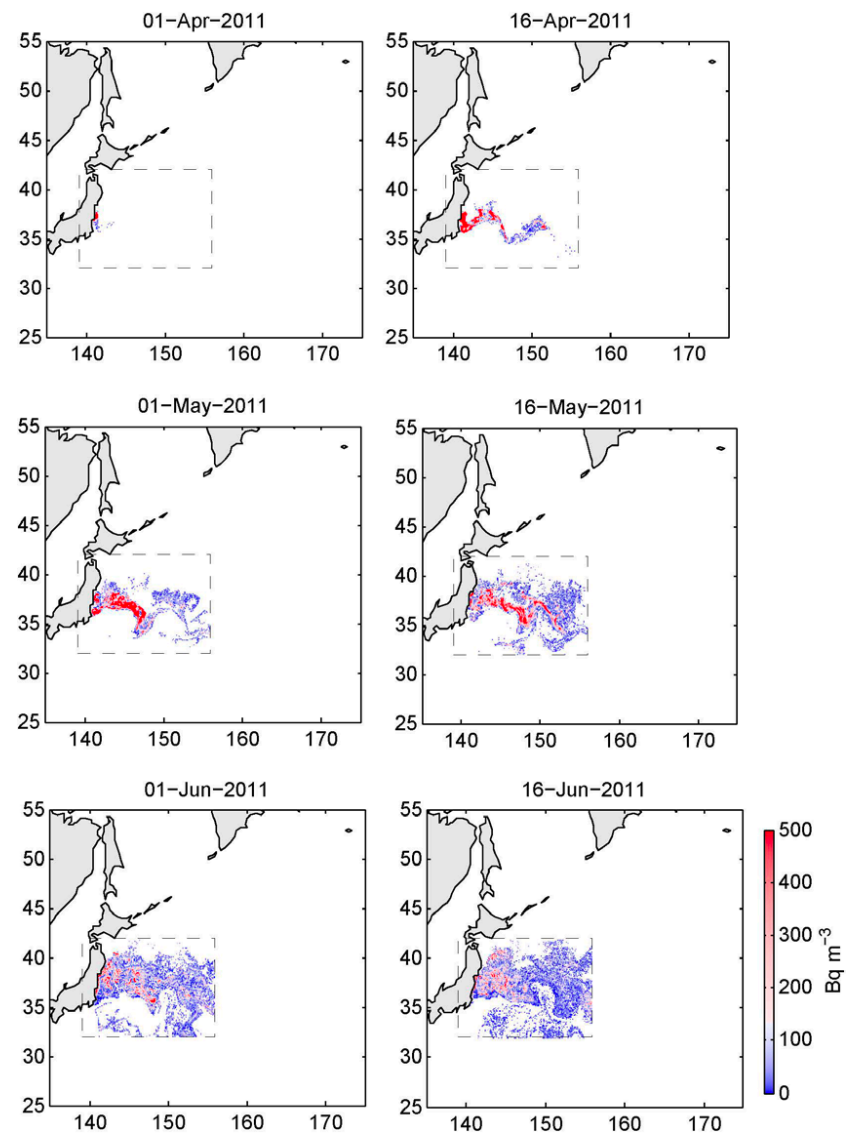

Fig. 10. Modeled ${ }^{137} \mathrm{Cs}$ concentration within the mixed layer on select dates from the oceanic source using 2-D NCOM velocities averaged over the top $25 \mathrm{~m}$. Dashed lines show the modeled domain. Source characteristics as in Fig. 5.

with the mean and standard deviation of $16.2 \pm 1.6 \mathrm{PBq}$ for the oceanic source, and $0-11 \mathrm{PBq}$ with the mean and standard deviation of only $0.5 \pm 2.7 \mathrm{PBq}$ for the atmospheric source. These values were determined by minimizing the data-model mismatch over the $K O K$ survey area. It is important to stress however that the $K O K$ observations are not well-suited for constraining the atmospheric source strength because most of the fallout ${ }^{137} \mathrm{Cs}$ had left the survey area by mid-June. Therefore, the reported atmospheric amplitude, especially its mean value, is possibly severely underestimated. The oceanic source amplitude, on the other hand, is well-constrained by the observed $K O K{ }^{137} \mathrm{Cs}$ concentrations, which are due almost entirely to the oceanic discharge.

Our oceanic source amplitude is more than four times that estimated by Tsumane et al. (2011, 2013), and about three times that estimated by Kawamura et al. (2011), Estournel et al. (2012) and Miyazawa et al. (2012). However, it agrees well with the estimate of 11 to $16 \mathrm{PBq}$ reported by Charette et al. (2013), is consistent with the $14.8 \mathrm{PBq}$ estimate obtained by Masumoto et al. (2012) based on the JCOPE model results, and is within the $10-34 \mathrm{PBq}$ range reported by Bailly du Bois et al. (2012). As a consistency check, combining the total ${ }^{137} \mathrm{Cs}$ inventory of $2 \mathrm{PBq}$ reported by Buesseler et al. (2011) with our model-based percentage of ${ }^{137} \mathrm{Cs}$ left in the $K O K$ area from the oceanic $(17.5 \%)$ and atmospheric $(4.5 \%)$ sources, and making use of the notion that about $95 \%$ of the measured ${ }^{137} \mathrm{Cs}$ inventory comes from the oceanic source, one can obtain an estimate of the total source amplitude of about $11 \mathrm{PBq}$ for the oceanic and $2.2 \mathrm{PBq}$ for the atmospheric sources. These numbers agree with our estimates, which were based on minimizing the data-model mismatch. Our highest atmospheric source strength is less than $50 \%$ of the lower limit of the Stohl et al. (2012) estimate. They reported a range of 23 to $50 \mathrm{PBq}$ for the atmospheric fallout. Finally, it is important to note that the deficiencies of our circulation model associated with its two-dimensional nature and coarse spatial and temporal resolution may potentially influence our estimates of the source strengths. Based on the similarity between the three-dimensional and two-dimensional NCOM runs (Sect. 4), it is concluded that the neglect of vertical velocities does not cause significant distortion of the mixed-layer distributions of radionuclides in the $K O K$ cruise area in June 2011. The lack of spatio-temporal resolution in the near-shore area, on the other hand, may cause the radioactive waters to leave the domain too soon, suggesting that our estimate may be an upper limit of the source strength. That being said, most estimates are subject to some deficiencies and our estimates provide the advantage that they present a good perspective on the range of values resulting from different models, methods and assumptions.

Several features of the measured ${ }^{137} \mathrm{Cs}$ field were explained through the modeling component of our investigation. First, the absence of ${ }^{137} \mathrm{Cs}$ at the southernmost stations was attributed to the Kuroshio Current, which acts as a transport barrier preventing the southward progression of ${ }^{137} \mathrm{Cs}$. Second, the largest concentrations of ${ }^{137} \mathrm{Cs}$ were shown to be associated with the semi-permanent near-shore eddy that was entraining ${ }^{137} \mathrm{Cs}$-rich coastal waters from the FNPP vicinity and retaining them through stirring around the eddy perimeter. This is in general agreement with Masumoto et al. (2012) who also commented on the importance of the mesoscale current structures for the spreading of Fukushima-derived radionuclides. Finally, the intermediate ${ }^{137} \mathrm{Cs}$ concentrations at the westernmost meridional column of stations were explained by the fact that these stations contained the more recent coolant water that had continued to leak from the reactor after the initial discharge. The pronounced non-uniform spatial structure of the measured ${ }^{137} \mathrm{Cs}$ fields is consistent with our modeling results, which suggest that the June distribution of ${ }^{137} \mathrm{Cs}$ was still streaky and patchy and was dominated by advection processes rather than by diffusion.

The 3-D effects of the vertical velocity and vertical shear were investigated through a comparison of the ${ }^{137} \mathrm{Cs}$ distributions from the fully 3-D NCOM velocities with those from the 2-D NCOM velocities averaged over the upper water column. The near-surface ${ }^{137} \mathrm{Cs}$ distributions from these two 

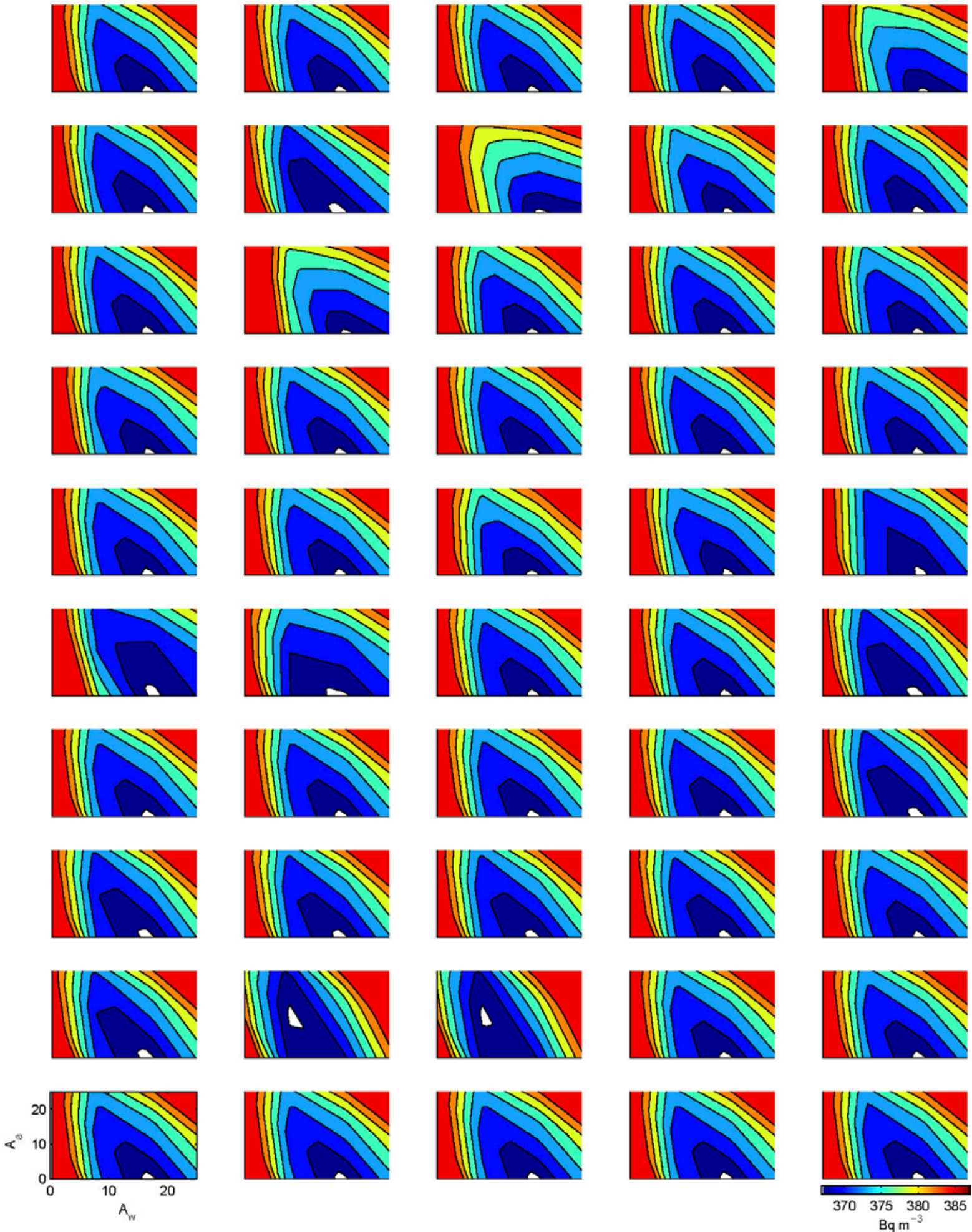

Fig. A1. Error function "Er" from Eq. (1) as a function of the oceanic and atmospheric source strengths, $A_{\text {atm }}$ and $A_{\text {ocean }}$, for 50 cases resulting from the bootstrapping procedure of sequentially eliminating one station at a time. The position of the minimum is indicated as a small white region in each panel. Color bars are slightly different for different subplots. To put the mean error values in perspective, the mean measured Cs concentration averaged over all stations is $415 \mathrm{~Bq} \mathrm{~m}^{-3}$. 
runs are similar, suggesting that vertical shear and vertical velocity play a secondary role in the short-term spreading of Fukushima-derived radionuclides. It also suggests that one could rely on the near-surface 2-D velocities to reproduce the major features of the short-term spreading of ${ }^{137} \mathrm{Cs}$.

In this research we have focused on the short-term dispersal of Fukushima-derived radionuclides, and on the assessment and interpretation of the $\mathrm{KOK}$ observations. The longterm spreading of the radionuclides throughout the Pacific Ocean, as well as the comparison and interpretation of other available measurements, are subjects of future study.

Although many attempts have been made to estimate the input source functions, which are of fundamental importance for assessing the aftermath of the Fukushima disaster, different methods yield different answers. As more independent estimates become available, it might be expected that the values will converge towards a single reliable number. We hope that our own investigation of the oceanic source amplitude will help to achieve this goal.

\section{Appendix A}

\section{Error function}

Figure A1 shows the structure of the error function "Er" defined by Eq. (1) as a function of the atmospheric and oceanic source strengths, $A_{\text {atm }}$ and $A_{\text {ocean }}$, for the 50 cases resulting from the bootstrapping procedure (i.e., sequentially eliminating one station and evaluating Eq. (1) for the remaining 50 stations). In all cases, the error function has a single minimum over the considered range of source amplitudes.

\section{Appendix B}

\section{Sensitivity study}

To illustrate the sensitivity of our results to the number particles released, Fig. B1 shows the comparison between the simulated mixed-layer ${ }^{137} \mathrm{Cs}$ concentrations from the direct discharge source on 20 June (the end of our numerical run) computed using different numbers of released water parcels. The upper panel with $2 \times 10^{7}$ particles is the baseline calculation, as this number of released particles that was used for the results presented in the text. The lower panel has twice the number of particles, $4 \times 10^{7}$ particles. The distributions of ${ }^{137} \mathrm{Cs}$ are similar in both cases and the concentration values $\left(c_{1}\right.$ and $c_{2}$ ) differ, on average, by only $8.4 \%$. The correlation, $\left\langle 2 c_{1} \cdot c_{2} /\left(c_{1}^{2}+c_{1}^{2}\right)\right\rangle$, between the two cases is also high and, ignoring ${ }^{137} \mathrm{Cs}$ concentration values below the detection limit, is equal to $95.2 \%$.
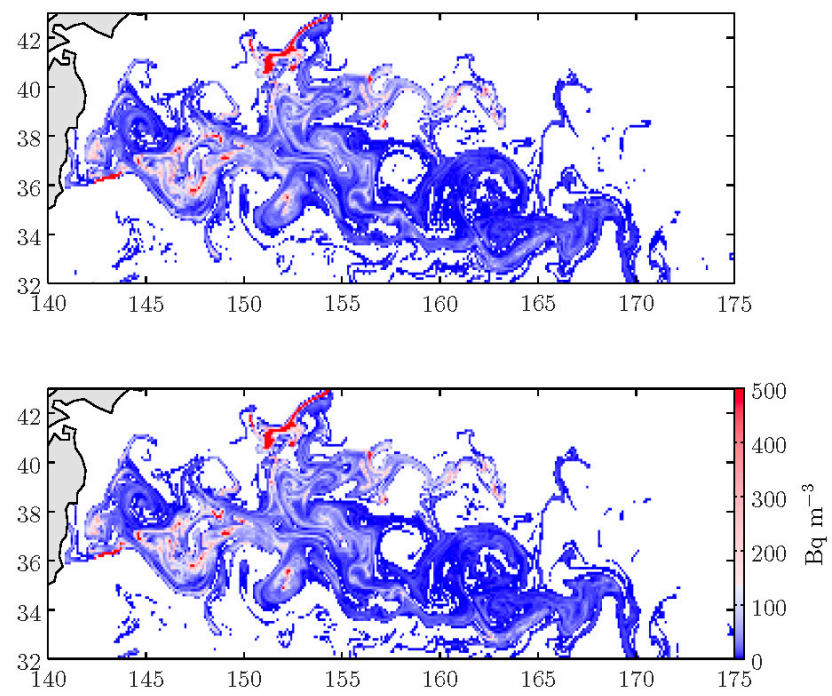

Fig. B1. Modeled ${ }^{137} \mathrm{Cs}$ concentration within the mixed layer on June 20 computed using $2 \times 10^{7}$ particles (top) and $4 \times 10^{7}$ particles (bottom). Colors, source domain and source strength as in Fig. 5. ${ }^{137} \mathrm{Cs}$ concentration values were cut off at the detection limit $\left(1.5 \mathrm{~Bq} \mathrm{~m}^{-3}\right)$.

Acknowledgements. We would like to thank Emanuel Coelho for his help with the NCOM data, and to acknowledge the NRL-Stennis Space Center for providing the NCOM output and support. Delia Arnold and Arturo Vargas are acknowledged for providing the atmospheric deposition. Irina Rypina was partially supported by Grant NSF-OCE-0725796. This work is funded by the Gordon and Betty Moore Foundation through Grant GBMF3007 to Ken Buesseler.

Edited by: P. Povinec

\section{References}

Bailly du Bois, P., Laguionie, P., Boust, D., Korsakissok, I., Didier, D., and Fiévet, B.: Estimation of marine source-term following Fukushima Dai-ichi accident, J. Environ. Radioact., 114, 2-9, 2012.

Barron, C. N., Kara, A. B., Hurlburt, H. E., Rowley, C., and Smedstad, L. F.: Sea surface height predictions from the Global Navy Coastal Ocean Model (NCOM) during 1998-2001, J. Atmos. Ocean. Tech., 21, 1876-1894, 2004.

Barron, C. N., Kara, A. B., Martin, P. J., Rhodes, R. C., and Smedstad, L. F.: Formulation, implementation and examination of vertical coordinate choices in the global Navy Coastal Ocean Model (NCOM), Ocean Model., 11, 347-375, 2006.

Beron-Vera, F., Wang, Y., Olascoaga, M., Goni, G., and Haller, G.: Objective detection of oceanic eddies and the Agulhas leakage, J. Phys. Oceanogr., in press, doi:10.1175/JPO-D-12-0171.1, 2013.

Browne, E., Firestone, R. B., and Shirley, V. S.: Table of Radioactive Isotopes, John Wiley \& Sons, Inc., New York, 1986

Buesseler, K. O., Aoyama, M., and Fukasawa, M.: Impacts of the Fukushima nuclear power plants on marine radioactivity, Environ. Sci. Technol., 45, 9931-9935, 2011. 
Buesseler, K. O., Jayne, S. R., Fisher, N. S., Rypina, I. I., Baumann, H., Baumann, Z., Breier, C. F., Douglass, E. M., George, J., Macdonald, A. M., Miyamoto, H., Nishikawa, J., Pike, S. M., and Yoshida, S.: Fukushima-derived radionuclides in the ocean and biota off Japan, P. Natl. Acad. Sci. USA, 109, 5984-5988, 2012.

Butler, D.: Radioactivity spreads in Japan, Nature, 471, 555-556, doi:10.1038/471555a, 2011.

Casacuberta, N., Masqué, P., Garcia-Orellana, J., Garcia-Tenorio, R., and Buesseler, K. O.: ${ }^{90} \mathrm{Sr}$ and ${ }^{89} \mathrm{Sr}$ in seawater off Japan as a consequence of the Fukushima Dai-ichi nuclear accident, Biogeosciences, 10, 3649-3659, doi:10.5194/bg-10-3649-2013, 2013.

Charette, M. A., Breier, C. F., Henderson, P. B., Pike, S. M., Rypina, I. I., Jayne, S. R., and Buesseler, K. O.: Radium-based estimates of cesium isotope transport and total direct ocean discharges from the Fukushima Nuclear Power Plant accident, Biogeosciences, 10, 2159-2167, doi:10.5194/bg-10-2159-2013, 2013.

Chelton, D. B., Schlax, M. G., Samelson, R. M., and de-Szoeke, R. A.: Global observations of large oceanic eddies, Geophys. Res. Lett., 34, L15606, doi:10.1029/2007GL030812, 2007.

Chino, M., Nakayama, H., Nagai, H., Terada, H., Katata, G., and Yamazawa, H.: Preliminary estimation of release amounts of ${ }^{131} \mathrm{I}$ and ${ }^{137} \mathrm{Cs}$ accidentally discharged from the Fukushima Daiichi nuclear power plant into the atmosphere, J. Nucl. Sci. Technol., 48, 1129-1134, doi:10.3327/jnst.48.1129, 2011.

Early, J. J., Samelson, R. M., and Chelton, D. B.: The evolution and propagation of quasigeostrophic ocean eddies, J. Phys. Oceanogr., 41, 1535-1555, 2011.

Eckart, C.: An analysis of the stirring and mixing processes in incompressible fluids, J. Mar. Res., 7, 265-275, 1948.

Egbert, G. D. and Erofeeva, S. Y.: Efficient inverse modeling of barotropic ocean tides, J. Atmos. Ocean. Tech., 19, 183-204, 2002.

Estournel, C., Bosc, E., Bocquet, M., Ulses, C., Marsaleix, P., Winiarek, V., Osvath, I., Nguyen, C., Duhaut, T., Lyard, F., Michaud, H., and Auclair, F.: Assessment of the amount of Cesium-137 released into the Pacific Ocean after the Fukushima accident and analysis of its dispersion in Japanese coastal waters, J. Geophys. Res., 117, C11014, doi:10.1029/2012JC007933, 2012.

High Energy Accelerator Research Organization: Measurement result of airborne nuclide and air radiation level in Tsukuba area, Tsukuba, Japan, available at: http://www.kek.jp/quake/ radmonitor/index-e.html, 2011.

Honda, M. C., Aono, T., Aoyama, M., Hamajima, Y., Kawakami, H., Kitamura, M., Masumoto, Y., Miyazawa, Y., Takigawa, M., and Saino, T.: Dispersion of artificial caesium-134 and -137 in the western North Pacific one month after the Fukushima accident, Geochem. J., 46, e1-e9, 2012.

Holte, J. and Talley, L.: A new algorithm for finding mixed layer depths with applications to Argo data and Subantarctic mode water formation, J. Atmos. Ocean. Tech., 26, 1920-1939, 2009.

Holte, J., Gilson, J., Talley, L., and Roemmich, D.: Argo mixed layers, Scripps Institution of Oceanography/UCSD (accessed July 2012), available at: http://mixedlayer.ucsd.edu, 2010.

Kawamura, H., Kobayashi, T., Furino, A., In, T., Ishikawa, Y., Nakamura, T., Shima, S., and Awaji, T.: Preliminary Numerical Experiments on Oceanic Dispersion of ${ }^{131}$ I and ${ }^{137} \mathrm{Cs}$ Discharged into the Ocean because of the Fukushima Daiichi Nu- clear Power Plant Disaster, J. Nucl. Sci. Tech., 11, 1349-1356, 2011.

Mancho, A. M., Small, D., and Wiggins, S.,: A tutorial on dynamical systems concepts applied to Lagrangian transport in oceanic flows defined as finite time data sets: Theoretical and computational issues, Phys. Rep., 437, 55-124, 2006

Masumoto, Y., Miyazawa, Y., Tsumune, D., Tsubono, T., Kobayashi, T., Kawamura, H., Estournel, C., Marsaleix, P., Lanerolle, L., Mehra, A., and Garraffo, Z. D.: Oceanic dispersion simulations of ${ }^{137} \mathrm{Cs}$ released from the Fukushima Daiichi Nuclear Power Plant, Elements, 8, 207-212, 2012.

Ministry of Education, Culture, Sports, Science, and Technology: Reading of radioactivity level in fallout by prefecture, Tokyo, available at: http://www.mext.go.jp/english/incident/1305529. htm, 2011.

Miyazawa, Y., Masumoto, Y., Varlamov, S. M., and Miyama, T.: Transport simulation of the radionuclide from the shelf to open ocean around Fukushima, Cont. Shelf Res., 50-51, 16-29, 2012.

MEXT: Japanese Ministry of Education, Culture, Sports, Science, and Technology: Reading of radioactivity level in fallout by prefecture, Tokyo. available at: http://www.mext.go.jp/english/ incident/1305529.htm, 2011a.

MEXT: Japanese Ministry of Education, Sports, Science and Technology: available at: http://radioactivity.mext.go.jp/en/1750/ 2011/08/1750_083014.pdf, 2011b.

Morino, Y., Ohara, T., and Nishizawa, M.: Atmospheric behavior, deposition, and budget of radioactive materials from the Fukushima Daiichi nuclear power plant in March 2011, Geophys. Res. Lett., 38, L00G11, doi:10.1029/2011GL048689, 2011.

NSCJ: Nuclear Safety Commission of Japan: Trial estimation of emission of radioactive materials (I-131, Cs-137) into the atmosphere from Fukushima Dai-ichi nuclear power station, Tokyo, available at: http://www.nsr.go.jp/archive/nsc/NSCenglish/geje/ 2011\%200412\%20press.pdf, 2011.

Ralph E. A. and Niiler, P. P.: Wind-driven currents in the tropical Pacific. J. Phys. Oceanogr., 29, 2121-2129, 1999.

Rypina, I. I., Pratt, L. J., Pullen, J., Levin, J., and Gordon, A.: Chaotic advection in an archipelago, J. Phys. Oceanogr., 40, 1988-2006, 2010.

Rypina, I. I., Pratt, L. J., and Lozier, S. M.: Near-surface transport pathways in the North Atlantic Ocean, J. Phys. Oceanogr., 41, 911-925, 2011.

Stohl, A., Seibert, P., Wotawa, G., Arnold, D., Burkhart, J. F., Eckhardt, S., Tapia, C., Vargas, A., and Yasunari, T. J.: Xenon133 and caesium-137 releases into the atmosphere from the Fukushima Dai-ichi nuclear power plant: determination of the source term, atmospheric dispersion, and deposition, Atmos. Chem. Phys., 12, 2313-2343, doi:10.5194/acp-12-2313-2012, 2012.

Toyoshima, K., Endo, T., and Hirayoshi, Y.: Measurement of ${ }^{134,137}$ Cs concentrations in the air of Fukushima-City, Reports of Science and Engineering, Saga University, 40, 3 pp., 2011.

TEPCO: Tokyo Electric Power Company: http://www.tepco.co.jp/ en/press/corp-com/release, 2011.

Tsumune, D., Tsubono, T., Aoyama, M., and Hirose, K.: Distribution of oceanic (137)Cs from the Fukushima Dai-ichi Nuclear Power Plant simulated numerically by a regional ocean model, J. Environ. Radioact., 10.1016/j.jenvrad.2011.10.007, 2011. 
Tsumune, D., Tsubono, T., Aoyama, M., Uematsu, M., Misumi, K., Maeda, Y., Yoshida, Y., and Hayami, H.: One-year, regionalscale simulation of ${ }^{137} \mathrm{Cs}$ radioactivity in the ocean following the Fukushima Daiichi Nuclear Power Plant accident, Biogeosciences Discuss., 10, 6259-6314, doi:10.5194/bgd-10-62592013, 2013.
Tukey, J. W.: Bias and confidence in not-quite large samples, Ann. Math. Stat., 29, 614 pp., 1958.

Wetherbee, G. A., Gay, D. A., Debey, T. M., Lehmann, C. M. B., and Nilles, M. A.: Wet deposition of fission-product isotopes to North America from the Fukushima Dai-ichi Incident, March 2011, Environ. Sci. Technol., 46, 2574-2582, 2011 